\title{
Taking back your turf: Understanding the role of law in medical decision making in opioid management (Part I-Overview)
}

\author{
Jennifer Bolen, JD
}

No clinician should ever feel like they have lost control of their medical decision making, especially when it comes to prescribing opioids and other controlled substances for the management of pain. Unfortunately, in today's healthcare system, clinicians engage in daily battles for control over their pain management practices, often wrestling with 1) healthcare benefit plans that do not provide benefits or cover services adequate or consistent with current, accepted clinical care standards and applicable legal/regulatory materials; 2 ) inadequate reimbursement for covered benefits and services; 3) lack of education by and information from state licensing board authorities; and 4) a legal/regulatory environment, including bullying and threats by patients, that often leaves the clinician afraid to prescribe opioids. This paper is the first in a series designed to help you understand legal/regulatory underpinnings for opioid management. I discuss only basic concepts due to space limitations and the sometimes complex nature of legal issues. My overall goal for the series is to enable you to make basic adjustments to office policies and medical record documentation so that you can "take back your turf" and prescribe opioids without fear of legal/regulatory sanction. ${ }^{1}$

\section{THREE GENERAL RULES}

To take back your turf, you must follow three basic rules-all designed to help you base your medical decision making on current, accepted clinical care standards and accurate and complete documentation, all within the existing legal/regulatory framework for controlled substance prescribing:

- Rule One: Read applicable federal and state guidelines, laws, and regulations related to the use of controlled substances in general and to the use of controlled substances for pain management. Keep these applicable materials in a notebook and update them quarterly.

- Rule Two: Stay current on accepted clinical care standards. Read appropriate journals and document your self-education. Attend continuing education events on the use of opioids for pain management.

- Rule Three: Develop and maintain a compliance program focused on assessing, selecting, and monitoring patients who take opioids for pain management. This compliance program should consider undertreatment of pain issues, your responsibility to minimize the potential for abuse and diversion of controlled substances, and patient accountability. Make sure your documentation incorporates and remains consistent with accepted clinical care standards and the current legal/regulatory framework identified through Rule One.

Obviously there is much more to taking back your turf, and these areas will be developed in future articles. The remainder of this article focuses on Rule OneIdentifying Basic Legal/Regulatory Materials on Controlled Substance Prescribing.

\section{IDENTIFYING BASIC LEGAL/REGULATORY MATERIALS ON CONTROLLED SUBSTANCE PRESCRIBING}

Clinicians rarely receive formal training in legal/regulatory issues related to controlled substance prescribing, and many clinicians have never read their licensing state's guidelines, laws, and regulations pertaining to these matters. The purpose of Rule One is to help you become familiar with the applicable federal and state guidelines, laws, and regulations related to the use of controlled substances in general and to the use of controlled substances for pain management. After reading these materials, you will use the notebook you make to evaluate your current office policies and medical record documentation on controlled substance prescribing.

There are two basic levels of legal/regulatory authorities for controlled substance prescribing: federal and state 


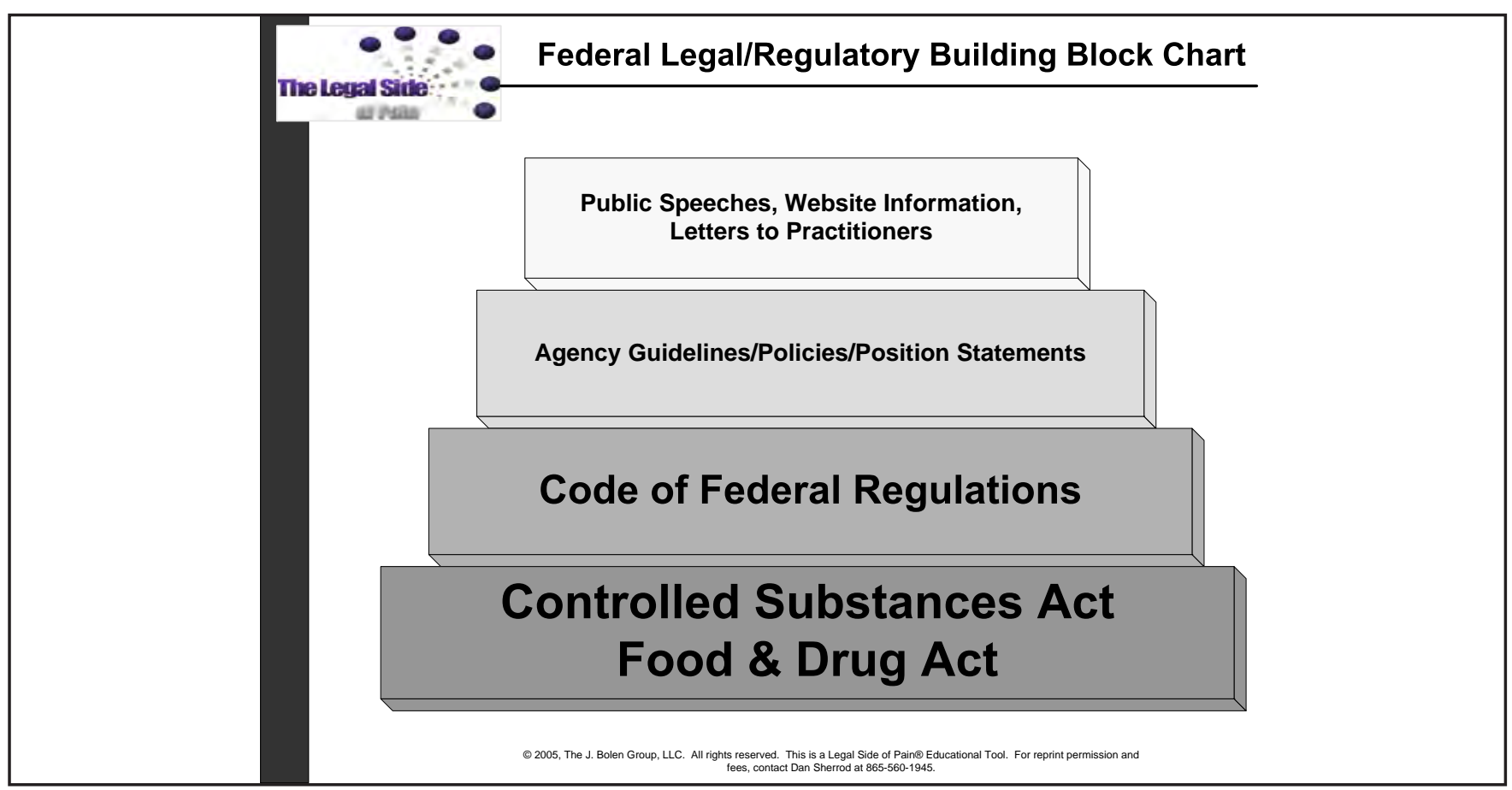

Figure 1. Federal Legal/Regulatory Building Block Chart.

governments and their agencies. Within the federal and state framework, there are three levels of legal/regulatory materials: laws, regulations, and guidelines/position statements [see Figure 1 (federal) and Figure 2 (state)]. I have given very basic definitions of laws, regulations, and guidelines here.

A law is usually embodied in a statute-federal or state. Examples include federal and state Controlled Substances Acts; state Medical, Nursing, and Pharmacy Practice Acts; state Intractable Pain Treatment Acts; and state Electronic Prescription Monitoring Acts. Laws like these form the base of the legal/regulatory pyramid for prescribing controlled substances in general and for pain management. Laws contain provisions that state the potential penalties, including civil and criminal sanctions, for failing to follow them. Laws give permission to federal and state agencies to regulate the flow of controlled substances and, with respect to state licensing boards, to protect the public by setting minimum expectations/standards for the practice of medicine and use of controlled substances for pain management. ${ }^{2}$

A regulation is usually embodied in a code or administrative rule. Regulations (sometimes called "rules") explain a corresponding law and set additional boundaries based specifically on the monitoring/sponsoring agency's interpretation of the law. Examples include the Code of Federal Regulations, which explains the Controlled Substances Act (CSA) of 1970, and gives the US Drug Enforcement Agency (DEA) oversight authority in this area. States have their own versions of regulatory codes explaining state controlled substances acts. Other examples include state administrative regulations governing the operation of licensing boards. Regulations give agencies additional permission to establish guidelines or other items further explaining the regulations. In some cases, state laws and regulations prohibit state licensing agencies from establishing guidelines or any materials. Regulations have the force of law, meaning that violating regulations normally results in sanctions, such as loss of licensing and civil fines and penalties. Some states have both regulations and rules.

A guideline contains an agency's position on a particular subject. Guidelines are not clinical care standards. Rather, agencies use guidelines to establish minimal expectations of licensees related to the specific subject matter. Guidelines are not laws and do not carry legal sanctions, such as civil or criminal penalties, but those who fail to follow guidelines may face administrative sanctions (e.g., licensing restrictions or educational orders) unless one can show good cause for the deviation from or failure to follow guidelines. Despite these basic distinctions between laws and guidelines, lawyers use guidelines to establish the framework of civil and criminal lawsuits, including medical malpractice and wrongful death cases. Guidelines sometimes contain directives and language that are outdated and inconsistent with current clinical care standards. It is important that you determine whether this is the case in your state. If so, I will provide a few ideas on how to handle out-ofdate guidelines later in this series. Finally, some states use position statements instead of guidelines, but their meaning and application is essentially the same. 


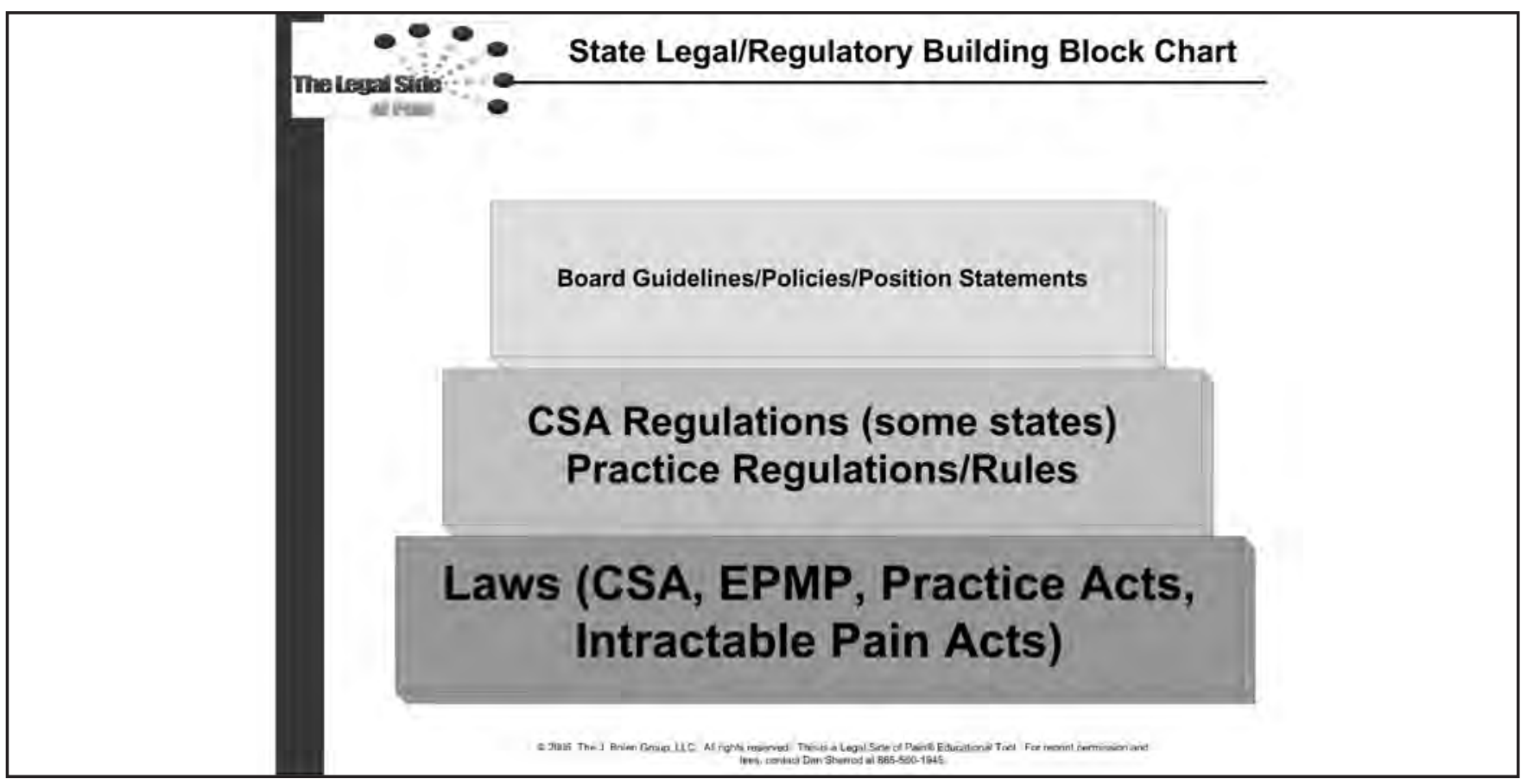

Figure 2.

\section{Basic federal Controlled Substances Act materials and principles}

The $\mathrm{CSA}^{3}$ is the primary body of federal law concerning several actions: administration, dispensing, manufacturing, and prescribing of controlled substances. Congress gave the DEA, a division of the US Department of Justice, the authority to administer the $\mathrm{CSA}^{4}$ and monitor the flow of controlled substances in this country.

The CSA lists drugs and chemicals subject to DEA control using five different schedules and miscellaneous provisions. The CSA contains the rationale for the classification and establishes different controls relating to the drugs listed in each schedule, ${ }^{5}$ and the rationale relates to potential for abuse and psychological and physical dependence. ${ }^{6}$ Controlled substances in Schedules II through V have an accepted medical use in the United States, and those in Schedule I do not. You can read more about these issues in the DEA's Pharmacist Manual. ${ }^{7}$

The CSA and supporting federal regulations do not limit the amount of drug that a physician can prescribe at one time. Likewise, the CSA does not establish "maximum doses" for controlled substances, does not limit the "life" of a controlled substance prescription, and does not limit the number of refills for controlled substance prescriptions under Schedules III through V. Some states, however, do have laws and regulations establishing limits in these areas. The CSA prohibits the refill of Schedule II prescriptions, and state law cannot deviate from the federal position here. The DEA has recently stated that the use of multiple Schedule II prescriptions with different fill dates is tantamount to circumventing the federal law prohibiting refills of Schedule II prescriptions. ${ }^{8}$

When a clinician/entity obtains a federal drug registration number, the DEA expects the registrant to follow federal laws, regulations, and policies pertaining to controlled substances. More specifically, the DEA expects clinicians to administer, dispense, and prescribe controlled substances for a legitimate medical purpose, within the usual course of professional practice. The DEA also expects clinicians to minimize the potential for abuse and diversion of controlled substances by adhering to applicable legal/regulatory boundaries and following current, accepted clinical care standards. ${ }^{9}$ When a registrant fails to meet these expectations, the DEA has two main avenues through which to pursue the noncompliant registrant: administratively, through the suspension or revocation of the registration; or criminally, through a federal indictment or information, depending on the facts and charges involved. The DEA acknowledges that state licensing authorities and the medical community as a whole define and maintain primary authority over medical decision-making principles. If the state system fails to enforce applicable laws, regulations, and guidelines, the DEA often ends up with these cases and takes action to protect the public from the illegal flow of controlled substances.

The DEA works through a network of Department of Justice attorneys and Assistant US Attorneys (collectively known as "federal prosecutors") when it pursues administrative action against or the criminal prosecution of a registrant. ${ }^{10}$ Over the last three years, federal actions 
against clinicians have included allegations of healthcare fraud and drug trafficking. These prosecutions have been very public and unfortunately served to divide the pain management community because of the positions taken by law enforcement entities and medical experts. All involved in pain management have a responsibility to minimize the potential for abuse and diversion of controlled substances while ensuring that pain does not go untreated. This balance is difficult for any clinician to achieve under our current healthcare system and legal/regulatory environment. Nonetheless, clinicians must take steps to understand the interplay here if they want things to change.

\section{Basic state materials and principles}

States have controlled substances laws (often called "Uniform Controlled Substances Acts" and found in state statutes), and most parallel the federal law. Most state controlled substances laws prohibit nonmedical use of controlled substances. Some states have additional schedules for drugs that present regional issues of abuse and diversion. Some states have electronic prescription monitoring programs (sometimes called "Electronic Prescription Accountability Acts"), and these laws are intended to allow clinicians to use a database to determine whether their patients receive controlled substances from other sources. ${ }^{11}$ Some states have Intractable Pain Treatment Acts and Patient Bill of Rights Acts, making it legal for a patient to request opioids for pain management, legal for clinicians to treat intractable pain using high doses of opioids and/or unusual combinations of drugs (but only if the clinician follows the law making up these acts), and legal for a clinician to refuse to treat patients with high doses or unusual combinations, as long as the refusing clinician points the patient in the direction of someone who does. ${ }^{12}$

When state licensing authorities grant healthcare professionals the privilege to practice, these authorities expect them to know and follow a body of guidelines, laws, and regulations, including those related to controlled substances. Most state licensing authorities publish these materials on Web sites and in handbooks. Some state boards even use law examinations to encourage healthcare professionals to learn and follow legal/regulatory materials. The organization of and terminology used by state authorities to refer to these materials varies, and a detailed discussion of these matters is beyond the scope of this paper. Clinicians should take time to identify and read their state's legal/regulatory materials pertaining to the use of controlled substances to treat pain and medical record documentation requirements. It is important to note that the federal law sets the outer parameters for legal matters pertaining to controlled substances.
Your state licensing board expects you to "control the flow of drugs" within the framework outlined by the federal and state legal/regulatory framework and according to accepted clinical standards. In the context of using controlled substances, especially opioids, for pain management, state licensing boards expect clinicians to take and document 1) the patient's history and a physical evaluation, 2) an individualized treatment plan, 3) an informed consent and treatment agreement, 4) a periodic review or patient follow-up justifying the continued use of the controlled substances, and 5) any relevant consultations and referrals. ${ }^{13}$ When a clinician loses control of his/her prescribing practices or fails to document the items listed here, he/she is inviting scrutiny from federal and state authorities.

\section{THE LEGAL SIDE OF PAIN® PROVIDER TOOLKIT: LEGAL/REGULATORY NOTEBOOK}

Use the checklist associated with this article (Appendix) to assemble a notebook containing basic legal/regulatory material on prescribing controlled substances and pain management. Read through these materials, and find a way to impart the basic principles to your medical staff. Keep a record of your efforts to educate yourself and your staff on these materials. If you have trouble finding some of these materials, use the Legal Side of Pain ${ }^{\circledR}$ Web site (http://www.legalsideofpain.com) or contact me for further assistance.

\section{CONCLUSION}

When you know where to find applicable legal/regulatory materials on controlled substance prescribing and pain management, it becomes easier to evaluate your current compliance position. Take time to assemble the materials described previously, as you will need them to work through Part II of this series. In all cases, remember to use controlled substances when there are clinical justifications for them, and document your clinical rationale according to the legal/regulatory framework previously discussed in general and more specifically set out by your state licensing authority. Do not fear law enforcement or licensing board intervention, and do not hesitate to ask questions when you do not understand what is required of you from a legal perspective. Remember that pain management is a process tied to the individual circumstances of each patient. Your medical decision making and documentation must reflect this individuality within the legal/regulatory framework of controlled substances and using them to manage pain.

Jennifer Bolen, JD, founder, The Legal Side of Pain ${ }^{\circledR}$, Knoxville, Tennessee. 


\section{NOTES}

1. I do not intend for this paper to serve as specific legal advice. Instead, this paper contains a general outline of legal/regulatory responsibilities and assumes that the clinician will only prescribe controlled substances for a legitimate medical purpose within the usual course of professional practice. If you have a specific legal question, make sure you get legal advice from an expert in this area.

2. State licensing board expectations/standards generally are not the same as accepted clinical care standards. However, these expectations/standards set minimal boundaries, and licensees should learn and follow these materials.

3. See Controlled Substances Act, Public Law 91-513, 84 Stat. 1242, codified as 21 USC 801, and sections following (1970).

4. See 21 CFR 1306.04(a) and 1306.07(c) (1996) (authorizing the DEA to monitor and regulate use of controlled substances for medical use).

5. See 21 USC 811-12, 823, and 829.

6. See 21 CFR 1306.

7. Available online at http://www.deadiversion.usdoj.gov.

8. The DEA made this comment in the Interim Policy Statement published in the Federal Register on November 16, 2004. The DEA is likely to issue a Final Policy Statement and may clarify its position on this matter.

9. The DEA most recently emphasized this responsibility in the Interim Policy Statement, November 16, 2004, as published in the Federal Register. The formal citation for this document is Federal Register: November 16, 2004, Vol. 69, No. 220, at Notices, Pages 67170-67172. You may find a copy of the Interim Policy Statement online via GPO Access ( $b t t p: / /$ wais.access. gpo.gov) using DOCID:fr16no04-82, or at http://www.legalsideofpain.com under "DEA Focus."

10. 21 USC 841; Recent cases include United States v. Hurwitz (Eastern District of Virginia), United States v. Knox (Western District of Virginia), United States v. Castle (Eastern District of Tennessee), and United States v. Michael Woodward, et al. (District of South Carolina). Each of these cases involves allegations of illegal drug trafficking through the issuance of prescriptions "outside the usual course of professional practice" and without a "legitimate medical purpose."

11. Not all states use electronic databases, and not all states have these. The terms of use of an electronic prescription monitoring program are described in state law and vary significantly. The DEA has published papers on these monitoring programs, and clinicians can use these papers to compare and contrast the various state programs. See http://www.deadiversion.usdoj.gov, and search for "prescription monitoring programs."

12. There are more requirements here. My comments are basic, and clinicians should learn whether their state has an Intractable Pain Treatment Act and/or Patient Bill of Rights and strive to understand the individual requirements of these laws. 13. These requirements will be discussed in more detail later in the series.

An invaluable resource in furthering pain management
through adequate opioid research and practice.




\section{APPENDIX. THE LEGAL SIDE OF PAIN` PROVIDER TOOLKIT: CHECKLIST OF BASIC ${ }^{\circledR}$ LEGAL/REGULATORY MATERIALS ON CONTROLLED SUBSTANCES AND PAIN MANAGEMENT}

\section{Federal materials:}

- Front page of DEA Diversion's Web site, at http:// www.deadiversion.usdoj.gov

- DEA's Interim Policy Statement

- Applicable sections of the Code of Federal Regulations (21 CFR 1306)

- Applicable sections of the US Code (21 USC 801 and following)

- DEA's Pharmacist Manual

\section{State materials:}

- Front page of your state licensing board's Web site

- Practice Act

- Controlled Substances Act, including criminal offenses relating to controlled substances

- Intractable Pain Treatment Act (if you have one)

- Patient Bill of Rights (if you have one)

- Electronic Prescription Accountability or Monitoring Act (if you have one)

- Practice Rules/Regulations

- Controlled Substances Rules/Regulations (if you have them)
- If you have them, Guidelines and/or Position Statements on the following:

- Pain Management

- Using Controlled Substances (or Opioids/ other individual substances) to Treat Pain

- Physician-Patient Relationship

- Ending the Physician-Patient Relationship or Patient Abandonment

- Medical Record Documentation

- Newsletters containing information about any of the above topics (you may have to search back several years)

\section{Miscellaneous materials:}

- Federation of State Medical Boards' Model Policy for the Use of Controlled Substances for the Treatment of Pain

- Federation of State Medical Boards' Model Policy for the Office-Based Treatment of Opioid Addiction

\section{NOTE}

1. I have listed only the basic materials in this checklist. You should review your state licensing board's Web site carefully to determine whether other materials may apply to your individual practice situation. 